\title{
Erratum to: The Impact of a Motor Affordance Intervention on Motor and Cognitive Development of Young Children
}

\author{
Asiye $\operatorname{Zoghi}^{1} \cdot$ Masomeh Shojaei $^{2} \cdot$ Abdollah Ghasemi $^{1}$
}

Published online: 25 January 2016

(C) Springer Science+Business Media New York 2016

\section{Erratum to: International Journal of Mental Health and Addiction DOI 10.1007/s11469-015-9616-4}

Please note that the given name of the third author of this article was misspelled in the article as originally published.

The correct spelling of Dr. Ghasemi’s first name is "Abdollah" (not “Abdolla”).

The online version of the original article can be found at http://dx.doi.org/10.1007/s11469-015-9616-4.

\section{Masomeh Shojaei}

a.zoqi.iau@gmail.com

1 Department of Physical Education Science and Research Branch, Islamic Azad University, Tehran, Iran

2 Department of Physical Education and Sport Sciences, Alzahra University, Vanak St., Tehran, Iran 